\title{
Trichomycosis in man penis and scrotum treated with colorants and inert powders plus abstringesnts
}

\section{Lorenzo Martini}

\author{
University of Siena, Department of Pharmaceutical Biotechnologies, Via A. Moro 2, 53100 Siena, Italy
}

Corresponding author: Lorenzo Martini, M.Sc., E-mail: martinil163@libero.it

\begin{abstract}
Initially it was believed to be uncommon in the inguinal region, although a huge series of papers have described trichomycosis particular to the inguinal area and have suggested that this disease is underestimated in the general population, and for this reason it has been finally baptized Trichomycosis pubis. Scope of my study is to approach the problem of Trichomycosis, that may be appropriately considered the real manifestation of a strange mix of fungi and cocci, where the prevalence of one or another is unclear and depends on too many factors, by the employ of only natural extracts included in porphirized inert powders, to abate the fungal component and azoic and triphenylmethanic colorants, to defeat coccal infection of penis: shaft, glans and scrotum. We have recruited a 35 y.old mason who has always suffered from hyperhidrosis at his pudenda.
\end{abstract}

Key words: Trichomonas pubis; Castellani tincture; Tinea imbricate; Chrysarobin extract; Magenta; Scarlet Blue

\section{INTRODUCTION AND STATE OF ART}

Trichomycosis is a fungal infection of the hair shaft that is found in areas bearing sweat glands, in particular the axillary area. Initially it was believed to be uncommon in the inguinal region, although a huge series of papers have described trichomycosis particular to the inguinal area and have suggested that this disease is underestimated in the general population, and for this reason it has been finally baptized Trichomycosis pubis [1-9].

First described in the axillary region by Paxton in 1869, but Castellani in 1911 [10] argued that this disease, discovered in pudenda of individuals native to Ceylon, could be attributable to Tinea imbricate Tokelau, fungus apt to colonize inguinal areas and the multiform and various Castellani tinctures have passed into the annals of history, indicated for treating appositely this odd fungus.

The A for instance had asserted that turpentine application was efficient even if however, the typical scales used to reappear. The A. referred that Cyllin ointment (20 to 50 per cent.) sometimes induced a temporary improvement, that Formalin had very good effect on localised patches. The usual 40 per cent solution of formaldehyde was applied with care, treating each time a small portion of the eruption, although Formalin often tended to cause severe pain and a certain amount of inflammation and apigmentation.

Even Chrysarobin ointment ( 5 to 10 per cent.) in repeated applications often induced strikingly rapid improvement in cases which were not of long standing. The eruption used to recommence, however, very-- shortly after its apparent disappearance. Chrysarobin was a very toxic medicament; the patient must be watched and the urine regularly examined. In one case symptoms of absorption appeared after a single application.

Salicylic acid and methyl salicylate had practically no action on the fungus.

Tinctura iodi and linimentum iodi: The former, freely applied, induced a very marked improvement, which, however, was not permanent. The latter was most effective where the patient were not a woman or a child with a skin too delicate to bear it.

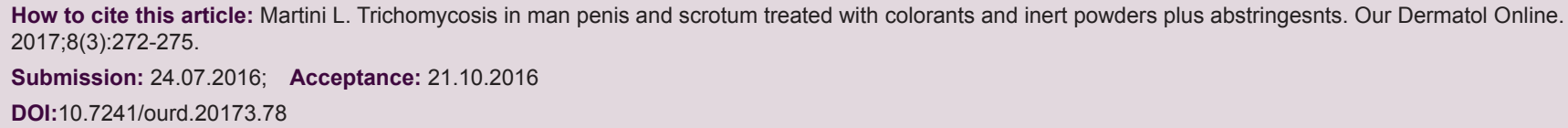


Resorcin and tincture of benzoin. Resorcin, either alone or mixed with salicylic acid in alcoholic solution and in ointments, showed not much effect. If, however, resorcin was dissolved in tincture of benzoin, very good results were obtained. It was notable that tincture of benzoin without resorcin had very little effect.

Resorcin dissolved in tinctura benzoini composita (60 to 120 gr. of resorcin to $1 \mathrm{oz}$. of the tincture of benzoin) was at the beginning of XX century the routine treatment of Tinea imbricata in the Colombo Clinic. It was applied freely once or twice daily on the affected regions.

Nowadays besides the fungal infection, that has amply certified, another causative role of multiple bacterial Corynebacterium species was finally established by Freeman et al in 1969 [6-10], notwithstanding the use of the term trichomycosis, and the implied causative role of fungi, has been always maintained. The colour differences noted at presentation of the condition, their association with particular corynebacteria, or the possible role of associated cocci have not been clarified, even if this relationship is not to be excluded, and, as we will observe in this seat itself, the co-presence of fungi and bacteria is more than probable.

The causative organism associated with most cases is Corynebacterium tenuis, which prefers the moist microenvironment of the inguinal regions. While as many as $33 \%$ of adults have colonization by bacteria in the inguinal or axillary regions, factors such as hyperhidrosis initiate more extensive growth and clinical manifestation. The exact origin of the cement substance that creates the grossly visible nodules is debated. Electron microscopy studies favour origin from the causative agents, while others have favoured elaboration from apocrine sweat.

While many patients are asymptomatic, several patients had accused trichomycosys of pubic rash, foul odour, or growths on the pubic hair and even incriminated coloured sweat, resulting in a consideration of chromhidrosis.

Patients typically present yellowish or red nodules on the hair shafts; even if yellow is most common. Sweat in the region tends to be coloured similarly. Lesions present in the inguinal region, often on the scrotum but occasionally on the base of the shaft of the penis. Lesions can be associated with erythema and itching, and superinfection with dermatophytes has been noted.
Risk factors appear to be geographic, with the highest incidence in tropic areas, and thus all the countries that overlook Mediterranean basin. In addition, poor hygiene often is present.

Trichomycosis is clinically differentiated from nits, lice, or fungal infection with a simple Wood light examination.

It is almost intuitive that treatment might be based on antibiotics (orally taken and/or topically taken) and topical pomades containing antifungal drugs.

Scope of my study is to approach the problem of Trichomycosis, that euphemistically could be designed as the manifestation of a cocktail of fungi and cocci, where the prevalence of one or another is unclear and depends on too many factors, by the employ of only natural extracts included in porphirized inert powders and colorants.

\section{MATERIALS AND METHODS}

An individual (35 y.old) asked to me to help him to treat a supposed malady inflicting his pudenda, where itching and a strong malodour were ravaging his groin.

He had used, as his private dermatologist suggested to him, an ointment made of ciclopiroxolamine $10 \%$ (in Montan wax, lanolin and ozokerite, to permit the complete adhesion to the shaft and scrotum even in case of hyperihidrosis, as waxes are hydrophobic at all).

Results though were mediocre and unsatisfying especially because high percentage of ciclopirox tended to redden and inflame more and more the groin.

By the simplest examination by Wood light I could declare I had to do with an important trichomycosis, even because the subject has been always since immemorial times suffering from hyperhidrosis.

Lesions like fissures were abundant in the area of the scrotum, accompanied by erythema diffusum and severe itch.

Glans and all the shaft of the penis itself were covered by slight reddish nodules.

First pace is to shave accurately the infested area (avoiding to use shaving foams containing camphor or menthol) and thus try to alleviate the hyperidrosis with 
drying agents, as inert powders plus natural antifungal dried extracts (Anethum graveolens or Anthemis auriculata), and advising the patient to wear boxers that permit a complete transpiration and exorcise sweat excess.

This first step is apposite to avoid fungal infection in all the inguinal area.

Second step consists in the usage of two different types of colorants, since it is still nowadays unclear the variety of plentitude of cocci colonizing the groin area: these are especially anaerobic, strictly Gram negative cocci comprising the genera Leptotricha or Butyriovibrium,(2) although, as I wrote before, even Corynebacteria, which are Gram positive, are involved.

Topical antimicrobials such as bacitracin, clindamycin or erythromycin are effective in most cases. Oral erythromycin may also be used.

For this reason it is advisable to alternate to types of colorants: the former elected against Gram positive bacteria (Magenta) and the latter against Gram negative bacteria (Scarlet).

The volunteer had to wash with an acid syndet his pudenda twice a day, dry it very scrupulously and then dredge accurately with the powder containing kaolin, kieselguhr and pulverized dill onto the scrotum and inner thighs.

In the morning he had to spread a tincture $(0.5 \%)$ of Magenta onto the entire shaft of the penis and let it dry off before to wear boxers.

After 9 hors, after having washed the penis with hydrogen peroxide $(8.5 \%$ ) he was prayed to spread a tincture $(05 \%)$ of Scarlet onto the entire shaft of the penis and repeat the same actions of the morning.

The successive morning, he had to repeat the with Magenta, after having washed with hydrogen peroxide at the same dilution. (w/w).

All these applications had to last one entire week, and after the fifth day it has been possible to observe the scrotum completely clean and free of lesions and fissures.

The very first day we counted the blisters present on the shaft of the penis and recorded the colour, keeping on account all the possible nuances of red, from the most inflamed till the palest, and it has been possible to assign the corresponding nuance to each colour that the remaining blisters presented at the lenticular examination.

Here follows the list of almost of the possible red colorations (in clinical observations).

1. Crimson

2. Mahogany

3. Persian red

4. Raspberry Red

5. Redwood Rose

6. Terracotta

7. Wine

8. Vermilion

9. Pink (flesh colored)

\section{RESULTS}

In Table 1, the number of the blisters counted every day before the morning treatment by Magenta.

Numbers represent the progressive day of treatment with Magenta and Scarlet colours.

Number NIL corresponds to the very first day, when the subject called at me for help him, and his Thricomycosis was at its manifest éclat.

The successive table II, plots all the nuances of the red spots We have observed day by day.

\section{DISCUSSIONS}

As most cases of Thricomycosis respond to therapy and however, recurrence in not uncommon, it is indeed suggestive to observe that in one sole week eleven blisters retrieved on the subject's penis and that were so red to appear Mahogany-coloured fully disappear by using the two colours: the former, the Magenta, that is indicated specifically against Gram positive bacteria and the latter, the Scarlet, that is exceptional against Gram negative.

The shading of the spots where the blisters ravaged grow progressively pinkish and flesh-coloured.

Table 1: Number of blisters counted onto the penis day after
day, keeping on account that NIL corresponds to the very
first day I encountered the subject who liked to undergo my
experimentation
\begin{tabular}{lccccccc}
\hline Nil & On & Two & Three & Four & Five & Six & Seven \\
\hline 11 & 9 & 8 & 8 & 7 & 4 & 3 & 0 \\
\hline
\end{tabular}


www.odermatol.com

Table 2: The nuances of red spotted every single day of treatment

\begin{tabular}{|c|c|c|c|c|c|c|c|}
\hline Nil & One & Two & Three & Four & Five & Six & Seven \\
\hline Mahogany & Crimson & Persian red & Wine & Redwood rose & Terracotta & Vermilion & Pink (flesh colored) \\
\hline
\end{tabular}

The subject asserts that after the fourth day he did not feel itchy.

Sweat was less intense and abundant after the second or third day.

Most cases respond to therapy; however, recurrence in not uncommon.

\section{AKNOWLEDGMENTS}

We have only thank the loyalty and the affiance of the mason who appreciated the proofs We asked him to do for my research, even he was tremendously shy and timid.

\section{REFERENCES}

1. Lestringant GG, Qayed KI, Fletcher S. Is the incidence of trichomycosis of genital hair underestimated? J Am Acad Dermatol. 1991;24(2 Pt 1):297-8.
2. Zaias N, Taplin D, Rebell GS. Final Report, Republic of Panama Medical Research. Washington, DC: Walter Reed Army Institute of Research; 1964.

3. Bargman H. Trichomycosis of the scrotal hair. Arch Dermatol. 1984;120:299.

4. Noble WC, Savin JA. Trichomycosis of the scrotal hair. Arch Dermatol. 1985;121:25.

5. Rosen T, Krawczynska AM, McBride ME, Ellner K. Naftifine treatment of trichomycosis pubis. Int J Dermatol. 1991;30:667-9.

6. Crissey JT, Rebell GC, Laskas JJ. Studies on the causative organism of trichomycosis axillaris. J Invest Dermatol. 1952;19:187-97.

7. Freeman RG, McBride ME, Knox JM. Pathogenesis of trichomycosis axillaris. Arch Dermatol. 1969;100:90-5.

8. McBride ME, Freeman RG, Knox JM. The bacteriology of trichomycosis axillaris. Br J Dermatol. 1968;80:509-13.

9. Paxton FV. On a disease condition of the hairs of the axilla, probably of parasitic origin. J Cutan Med. 1869;3:133.

10. Castellani A. Trichomycosis flava, nigra and rubra of the pubic regions. Br J Dermatol. 1911;23:341-74.

Copyright by Lorenzo Martini. This is an open access article distributed under the terms of the Creative Commons Attribution License, which permits unrestricted use, distribution, and reproduction in any medium, provided the original author and source are credited.

Source of Support: Nil, Conflict of Interest: None declared. 